\title{
WinRT Revealed
}

Michael Mayberry 


\section{WinRT Revealed}

Copyright (C) 2012 by Michael Mayberry

This work is subject to copyright. All rights are reserved by the Publisher, whether the whole or part of the material is concerned, specifically the rights of translation, reprinting, reuse of illustrations, recitation, broadcasting, reproduction on microfilms or in any other physical way, and transmission or information storage and retrieval, electronic adaptation, computer software, or by similar or dissimilar methodology now known or hereafter developed. Exempted from this legal reservation are brief excerpts in connection with reviews or scholarly analysis or material supplied specifically for the purpose of being entered and executed on a computer system, for exclusive use by the purchaser of the work. Duplication of this publication or parts thereof is permitted only under the provisions of the Copyright Law of the Publisher's location, in its current version, and permission for use must always be obtained from Springer. Permissions for use may be obtained through RightsLink at the Copyright Clearance Center. Violations are liable to prosecution under the respective Copyright Law.

ISBN 978-1-4302-4584-1

ISBN 978-1-4302-4585-8 (eBook)

Trademarked names, logos, and images may appear in this book. Rather than use a trademark symbol with every occurrence of a trademarked name, logo, or image we use the names, logos, and images only in an editorial fashion and to the benefit of the trademark owner, with no intention of infringement of the trademark.

President and Publisher: Paul Manning

Lead Editor: James Markham

Technical Reviewer: Jeff Sanders

Editorial Board: Steve Anglin, Ewan Buckingham, Gary Cornell, Louise Corrigan, Morgan Ertel, Jonathan Gennick, Jonathan Hassell, Robert Hutchinson, Michelle Lowman, James Markham, Matthew Moodie, Jeff Olson, Jeffrey Pepper, Douglas Pundick, Ben Renow-Clarke, Dominic Shakeshaft, Gwenan Spearing, Matt Wade, Tom Welsh

Coordinating Editor: Debra Kelly

Copy Editor: William McManus

Compositor: name?

Indexer: name?

Artist: name?

Cover Designer: Anna Ishchenko

Distributed to the book trade worldwide by Springer Science+Business Media New York, 233 Spring Street, 6th Floor, New York, NY 10013. Phone 1-800-SPRINGER, fax (201) 348-4505, e-mail orders-ny@springer-sbm.com, or visit WWW. springeronline.com.

For information on translations, please e-mail rights@apress.com, or visit www.apress.com.

Apress and friends of ED books may be purchased in bulk for academic, corporate, or promotional use. eBook versions and licenses are also available for most titles. For more information, reference our Special Bulk Sales-eBook Licensing web page at wW. apress.com/bulk-sales.

The information in this book is distributed on an "as is" basis, without warranty. Although every precaution has been taken in the preparation of this work, neither the author(s) nor Apress shall have any liability to any person or entity with respect to any loss or damage caused or alleged to be caused directly or indirectly by the information contained in this work. 
To Grandpa Hyde, thanks for buying my first computer. 


\section{Contents at a Glance}

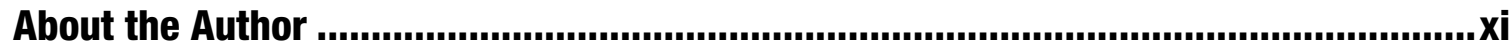
About the Technical Reviewer ............................................................................. xifi

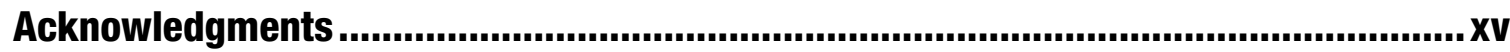

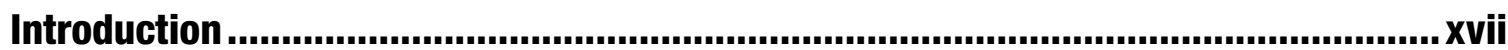

Chapter 1: Introducing WinRT...........................................................................1

Chapter 2: Building WinRT Components ........................................................11

Chapter 3: Building a .NET App with WinRT..........................................................29

Chapter 4: Reaching Beyond the App ..............................................................47

Appendix: WinRT Resources.....................................................................69

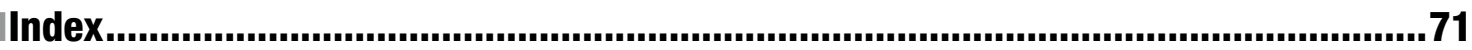




\section{Contents}

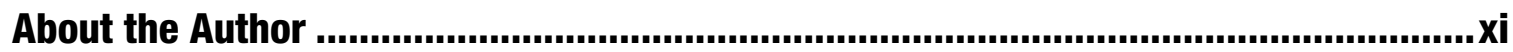
About the Technical Reviewer ............................................................................. xifi

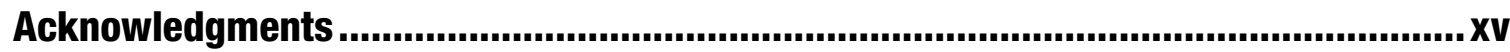
Introduction ..................................................................................................... xvii

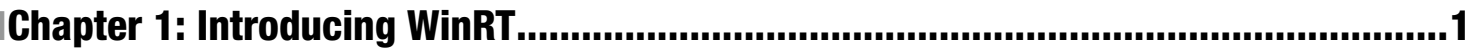

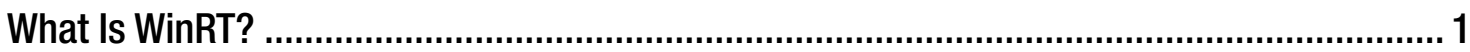

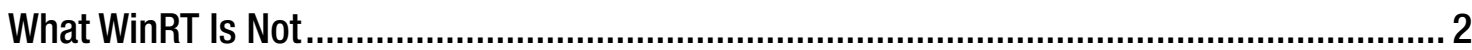

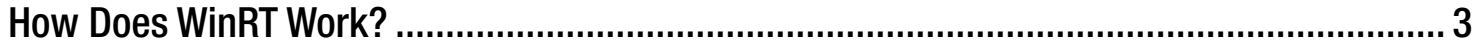

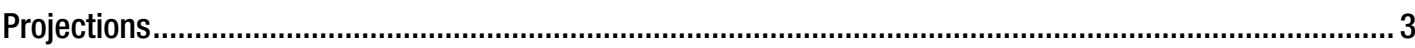

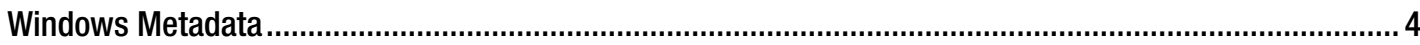

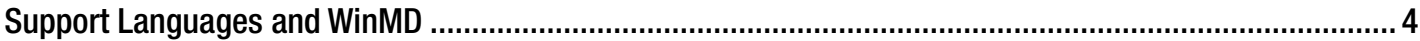

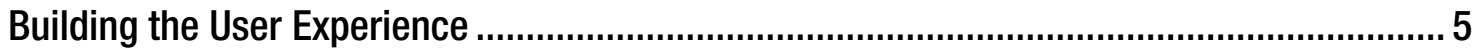

XAML

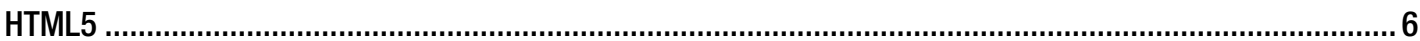

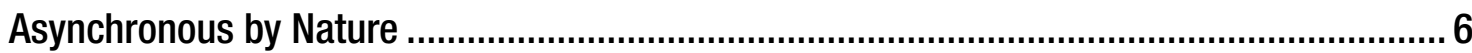

The WinRT API

Summary 
Chapter 2: Building WinRT Components

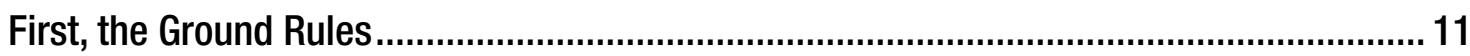

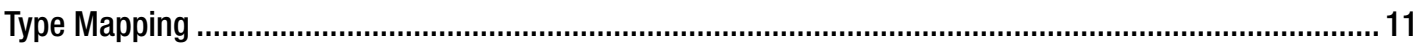

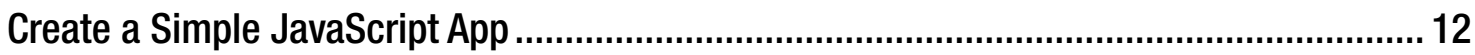

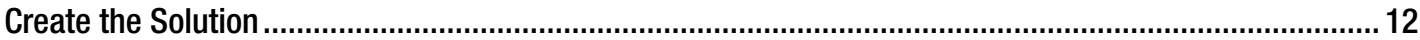

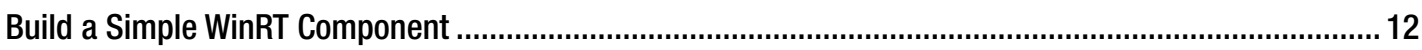

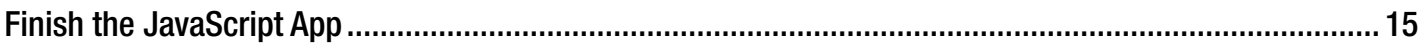

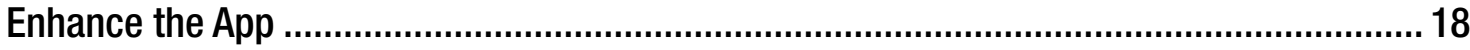

Add a Method to the WinRT Component ........................................................................................... 19

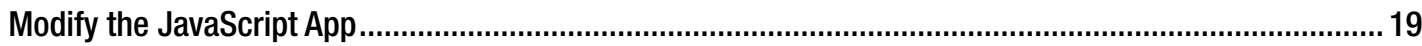

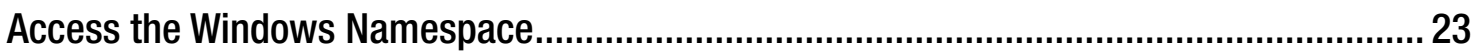

Summary

Chapter 3: Building a .NET App with WinRT...........................................................29

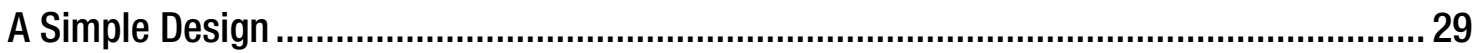

Create the Solution

Build the $\mathrm{UI}$

Make the App Work

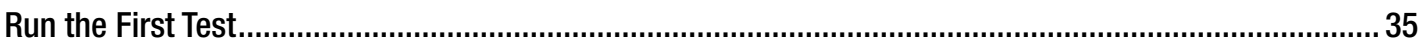

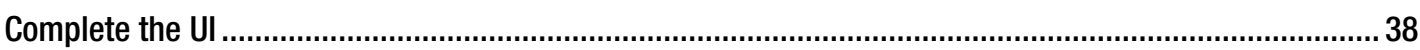

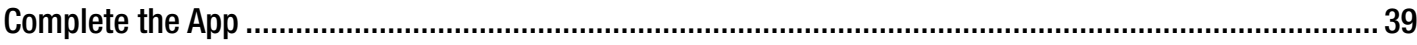

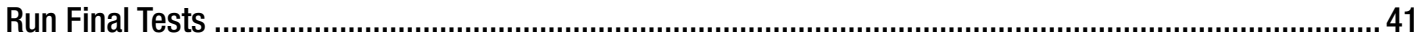

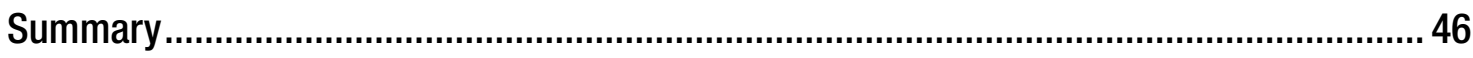

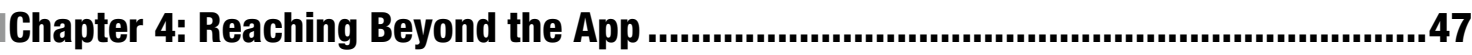

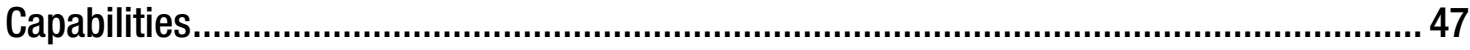

The Manifest Designer................................................................................................................. 47

The Available Capability Options...................................................................................................... 48

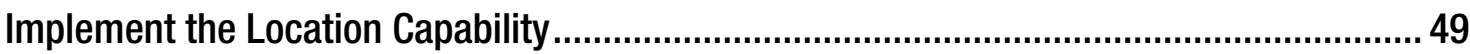

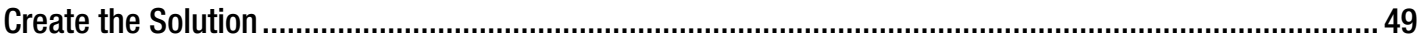

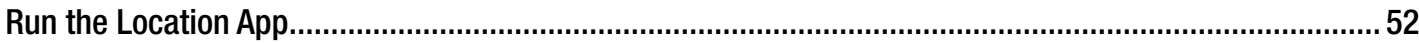




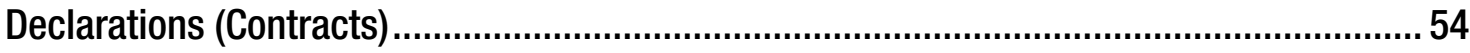

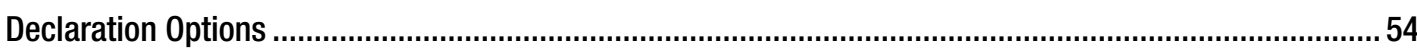

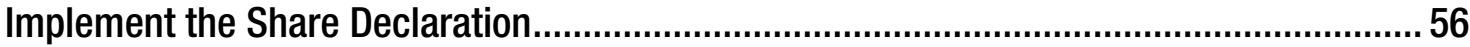

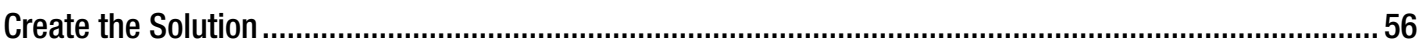

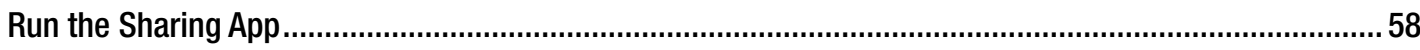

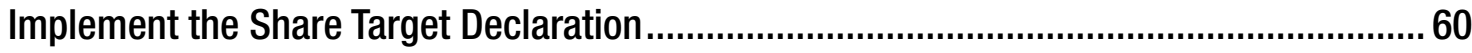

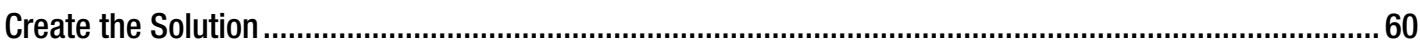

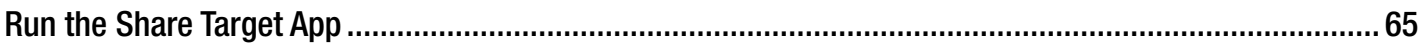

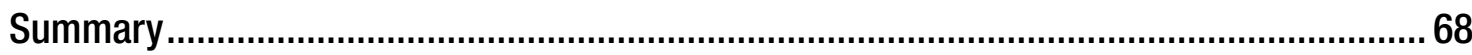

Appendix: WinRT Resources ......................................................................................69

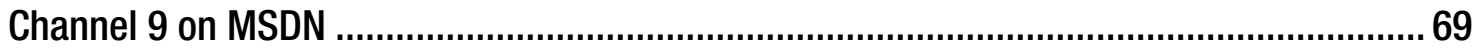

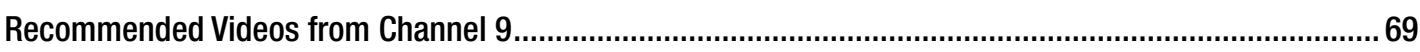

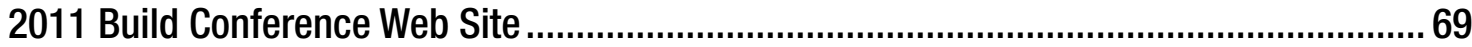

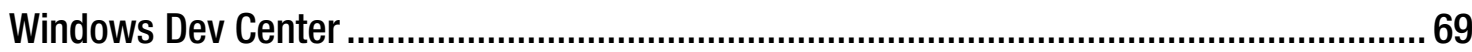

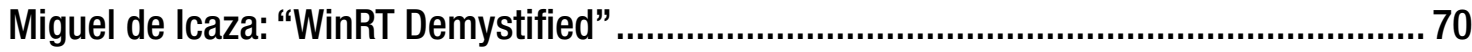

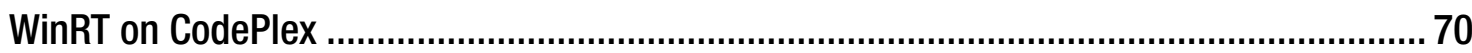

Doug Steven: "A Bad Picture Is Worth a Thousand Long Discussions" ...............................70

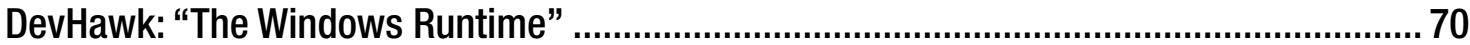




\section{About the Author}

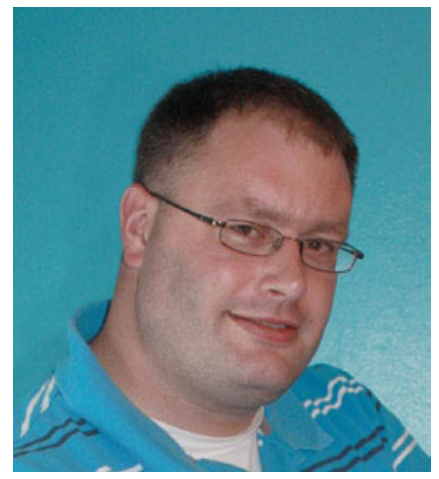

For questions and comments, contact Michael at michaelmayberry@hotmail.com.
Michael Mayberry has been developing software with Microsoft technologies for more than 13 years. Over those years he has consistently adopted new solutions and tools to solve increasingly larger problems.

Michael currently serves as a software architect for a large nonprofit organization in the Dallas-Fort Worth area. He has become an expert in integration, providing solutions that allow new software to interact with existing systems. His experiences range from content management systems to data warehouses to CRM systems.

Michael has always valued team building and sharing his knowledge with others. Recently, he expanded his focus to include writing and reviewing. He has been a technical reviewer for many projects and coauthored one other book.

When he is not working, Michael enjoys spending time with his beautiful wife and four children. 


\section{About the Technical Reviewer}

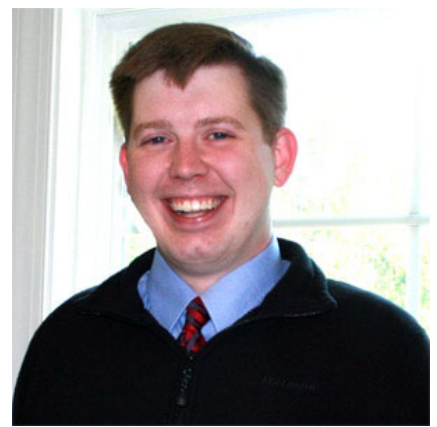

Jeff Sanders is a published author, technical editor, and accomplished technologist. He is currently employed with Avanade in the capacity of a group manager/senior architect.

Jeff has years of professional experience in the field of IT and strategic business consulting, leading both sales and delivery efforts. He regularly contributes to certification and product roadmap development with Microsoft and speaks publicly on Microsoft enterprise technologies. With his roots in software development, Jeff's areas of expertise include collaboration and content management solutions, operational intelligence, digital marketing, distributed component-based application architectures, object-oriented analysis and design, and enterprise integration patterns and designs.

Jeff is also the CTO of DynamicShift, a client-focused organization specializing in Microsoft technologies, specifically Office365/BPOS, SharePoint Server, StreamInsight, Windows Azure, AppFabric, Business Activity Monitoring, BizTalk Server, and .NET. He is a Microsoft Certified Trainer, and he leads DynamicShift in both training and consulting efforts.

He enjoys non-work-related travel and spending time with his wife and daughter, and he wishes he had more time for both.

Jeff may be reached at jeff.sanders@dynamicshift.com. 


\section{Acknowledgments}

I first bow my head in thanks to Jesus Christ for giving meaning to life and providing the way for us to see the love God has for us all. Thank you for the blessings that make a project like this even possible.

I thank my wife, Camille. She makes our home a great place to work, write, and play. Thank you for your encouragement and support.

Thank you to everyone at Apress who worked so hard to make this project happen so quickly. I truly appreciate your effort in making this book possible. 


\section{Introduction}

Windows 8 provides a new and exciting platform for developers. This coming version of Windows promises to run on new hardware, such as tablets, as well as existing laptops and desktops. Microsoft has developed a new layer for accessing and leveraging system resources, including the operating system services. The new Windows Runtime (WinRT) is this layer.

\section{Who Is This Book For?}

This book is an introduction to WinRT. With the Windows Runtime being so new, developers of all experience ranges can benefit from this introduction. This book demonstrates how to build Windows 8 Metro style apps, specifically focusing on WinRT.

\section{How This Book Is Structured}

There are only four chapters in this book, but each one is packed with information designed to get developers familiar with WinRT.

This short book begins with an overview of WinRT in the first chapter, which explains what WinRT is and answers common questions developers have about the Windows Runtime.

The following chapter demonstrates coding with WinRT. The first examples start simple and show how WinRT components are built.

The final two chapters focus on building Metro style apps. The developer builds apps that use WinRT components to interface with the user. They also extend their app to interact with other apps.

\section{Downloading the Code}

The code for the examples shown in this book is available on the Apress web site, www. apress. com. A link can be found on the book's information page under the Source Code/Downloads tab. This tab is located underneath the Related Titles section of the page. 